\title{
Peer Irrigators and the Choice of Field Management and Water Control Practices for Irrigation in Arkansas
}

\author{
Victoria Bailey ${ }^{1}$, Kent Kovacs ${ }^{1, *}$, Christopher Henry ${ }^{2}$, Qiuqiong Huang ${ }^{1}$ and Larry J. Krutz ${ }^{3}$ \\ 1 Department of Agricultural Economics and Agribusiness, University of Arkansas, \\ Fayetteville, AR 72701, USA; pbailey96@icloud.com (V.B.); qqhuang@uark.edu (Q.H.) \\ 2 Rice Research and Extension Center and Department of Biological and Agricultural Engineering, \\ University of Arkansas, Fayetteville, AR 72701, USA; cghenry@uark.edu \\ 3 Mississippi Water Resources Research Institute, Mississippi State University, Starkville, MS 39762, USA; \\ j.krutz@msstate.edu \\ * Correspondence: kkovacs@uark.edu; Tel.: +1-479-575-2323
}

Citation: Bailey, V.; Kovacs, K.; Henry, C.; Huang, Q.; Krutz, L.J. Peer Irrigators and the Choice of Field Management and Water Control Practices for Irrigation in Arkansas. Agronomy 2021, 11, 2473. https:// doi.org/10.3390/agronomy11122473

Academic Editor: Alejandro Galindo

Received: 28 October 2021

Accepted: 1 December 2021

Published: 4 December 2021

Publisher's Note: MDPI stays neutral with regard to jurisdictional claims in published maps and institutional affiliations.

Copyright: (c) 2021 by the authors. Licensee MDPI, Basel, Switzerland. This article is an open access article distributed under the terms and conditions of the Creative Commons Attribution (CC BY) license (https:/ / creativecommons.org/licenses/by/ $4.0 /)$.

\begin{abstract}
We examined how irrigation techniques in use by family and friends influence the use and share of land utilizing different irrigation techniques by Arkansas producers. A bivariate sample selection model simultaneously estimated how farm characteristics determine the use and explain the share of a farm that utilizes an irrigation technique. We found that the irrigation techniques in use by family and friends do affect the irrigation techniques a producer uses and the share of acres utilizing different irrigation techniques. A producer with a family or friend that uses end-blocking irrigation is $41 \%$ more likely to use end-blocking themselves. Having a family or friend who uses pivot irrigation technology tends to decrease the share of irrigated acres that utilizes end block irrigation by 0.211 . We also found that when the irrigation techniques in use by family and friends interact with variables such as location and participation in a regional conservation partnership program, the effects on the producer's decision vary. The share of irrigated acres that use cutback irrigation decreases by 0.21 for a producer who has a peer that uses irrigation scheduling. However, if the producer lives along Crowley's Ridge and has a peer that uses irrigation scheduling, the share of irrigated acres that use cutback irrigation decreases by an additional 0.54 .
\end{abstract}

Keywords: technology choice; social learning; border irrigation; precision grading; cutback irrigation; deep tillage

\section{Introduction}

Increasing demands of water for fibers, biofuels, and other products driven by population and economic growth have highlighted the potential limitations on water supplies for agriculture [1]. Finding ways to make irrigation more efficient is imperative to maintain production levels with fewer water resources. The analysis of adoption and diffusion patterns of irrigation technologies is the core of several empirical studies in developing and developed countries [2]. Many studies have provided clear evidence of economic factors, demographic characteristics, and environmental conditions with results explaining their influence on the use of irrigation technologies [3-6]. Many prior studies have also measured the influence that friends, family, extension agents, etc. have on a producer's use of varying agriculture technologies [7-9], while few studies have evaluated the influence of friends and family on the use of irrigation technologies. This paper is an effort to merge these two approaches and provide additional information, to the current literature, concerning the effects of friends and family on the use of different irrigation technologies. We examined whether social interactions or relationships with family, friends, and other producers (peer network) influence the use of specific irrigation technologies, while controlling for crop choice, current irrigation systems, and demographic characteristics. We examined not only the peer effects on the use of irrigation techniques but also the share of irrigated 
land on each farm utilizing these techniques. We further explored the heterogeneity in peer influence by considering how the peer influence depends on the sub-region in Arkansas and a producer's participation in conservation programs.

Much of the literature on peer-effects has found that close proximity will increase the likelihood of adopting similar technologies, and increasing the distance lowers the likelihood [7-9]. The sheer number of friends or family that use a particular technology increase the likelihood of adopting the technology; however, when the number of friends or family is greater than ten, the likelihood still increases but at a diminishing rate $[10,11]$. The study of Ref. [12] found that when a producer heard good news about a fertilizer, they were more likely to change their use, and when a producer heard bad news about a fertilizer, they were less likely to change their use. The results on extension agent services in technology adoption are somewhat mixed. The study of Ref. [7] found that extension visits positively affect the adoption of new technologies, while other studies in the literature $[12,13]$ have suggested that extension agent visits or trips to the office have a negative or insignificant effect on technology choice.

The Alluvial Aquifer lies along the lower portion of the Mississippi River Delta. It is closer to the surface than other surrounding aquifers and is primarily used for irrigation. The average depth is 50 feet deep; it can reach up to 150 feet deep in some areas, and there are roughly 19,000 square miles of groundwater in Arkansas [14]. Rice, soybeans, and cotton are in the top five agriculture products based on revenue generated in these areas. It is important for producers to utilize efficient irrigation practices, to continue to irrigate their crop without depleting the water source. There were 4,246,491 acres irrigated in Arkansas as of 2018. This is lower than the number of acres in 2012, which was 4,803,902 acres being irrigated $[15,16]$. This decrease in the number of irrigated acres could be attributed to an increase in rainfall. The United States drought monitor observed a moderate to exceptional drought widespread throughout Arkansas that lasted 101 weeks in 2010-2012, with an exceptional drought affecting 53\% of the state in August of 2012 [17]; therefore, fields that normally go unwatered were irrigated.

Field management practices include zero grade leveling, end blocking, deep tillage, warped surface leveling, and precision grade leveling. Water flow control technologies consist of alternative wetting and drying, multiple inlet irrigation, surge irrigation, flowmeters, computerized hole selection, border irrigation, border irrigation, and cutback irrigation. The water recovery or storage technologies include tail-water recovery and reservoirs, while the supplemental irrigation technology is computerized irrigation scheduling. Our sprinkler irrigation only consists of pivot irrigation. In Arkansas, $16 \%$ of irrigated farms use tail-water recovery or alternative row irrigation, $20 \%$ of irrigated farms use precision leveling, $5 \%$ of irrigated farms use shorter furrow lengths, $1 \%$ of irrigated farms use surge flow, $72 \%$ of irrigated farms use a form of poly pipe irrigation, $6 \%$ of irrigated farms use other drip irrigation systems, $84 \%$ of irrigated farms use gravity irrigation systems, and $23 \%$ use sprinkler irrigation systems [18-20]. The top three barriers to making improvements that conserve water were reported as: the producer cannot finance the improvements (30.5\%), the landlord will not share the cost $(30 \%)$, or the improvements will not reduce the cost enough to cover the installation costs (25.8\%) [21]. There are some programs that have been enacted to assist in irrigation or drainage improvements. The USDA has programs such as Environmental Quality Incentives, Regional Conservation Partnership, and Conservation Innovation Grants for water conservation, and Conservation Stewardship, Conservation Reserve, Wetlands Reserve, and Grassland Reserve Stewardship; these programs have $78 \%$ and $53 \%$ of the eligible farms in Arkansas participating, respectively [22]. This is better than the United States as a whole; $52 \%$ of the eligible farms participated in water conservation programs, and $12 \%$ of eligible farms participated in stewardship programs as of 2018 [22].

Understanding how peer networks affect a producer's decision to use new or different irrigation practices could help policymakers form programs and regulations that could steer the use of specific practices. Policymakers interested in reducing erosion might 
distribute information pamphlets about precision grade leveling to producers participating in regional conservation programs. The reason for this is that our findings reveal that producers in the regional conservation program have a predisposition to use a larger share of farmland with precision grade leveling. Extension agents could also target producers more receptive to an irrigation practice. For example, producers living in the South Delta might have a larger share of farmland utilizing warped surface leveling, except our finding showed areas where flow meter use is common. If an extension agent then wants to increase the share of farmland using warped surface leveling, they would send agents to South Delta but avoid areas with greater flow meter use.

\section{Materials and Methods}

We describe the data first, followed by an explanation of the statistical methods.

\subsection{Data}

The data were from the Arkansas Irrigation Use Survey, which was completed in October 2016. The survey was conducted through a collaboration of state irrigation specialists at the University of Arkansas, Mississippi State University, University of Missouri, and Louisiana State University with funding from the United Soybean Promotion Board and Arkansas Soybean Promotion Board [23]. The Mississippi State University Social Science Research Center administered the survey via phone interviews. The prospective survey respondents were found in the water user database managed by the ANRC, with the commercial crop growers identified by Dun \& Bradstreet records for the state of Arkansas. There were 3712 eligible participants contacted: 842 were disabled numbers, 1321 were not answered and had a busy signal or went to voicemail, and 925 contacts were ineligible due to illness or language barriers, which led to 624 accessible contacts being eligible to complete the survey. During the follow-up call of the 255 contacts who declined to participate, 7 did not complete the survey although they scheduled callbacks, and 171 discontinued the survey. In the end, 199 producers completed the survey in full; therefore, this survey's response rate was between $6.87 \%$ and $32.25 \%$. The questionnaire had close to 150 questions and took respondents an average of 30 to $40 \mathrm{~min}$ to finish via phone.

The dependent variables used in the participation and outcome equations are described in Table 1. The first portion gives the variables used in the participation equation. These are binary variables that equal to 1 if used and 0 otherwise. Precision Grade Leveling (PrecisionGrade) was the most common irrigation practice, with $84 \%$ of respondents indicating that they use precision grade leveling on their farm. Furthermore, $13 \%$ of respondents use border irrigation systems (Border), $25 \%$ of the respondents reported using end block irrigation systems (Endblock), and 8\% of the respondent's farms reported using cutback irrigation systems (Cutback). Those who use warped surface leveling (WarpedSurface) formed $25 \%$ of the dataset, and $35 \%$ of respondents use deep tillage (DeepTillage).

The dependent variables for the outcome equation are described in the second portion. These are continuous variables that indicate the percentage of land using a particular practice. Precision grade leveling (Percent_PrecisionGrade) and border irrigation (Percent_Border) systems were reported by participants to be used on the largest portions of irrigated land, that is $56 \%$ and $53 \%$, respectively. Cutback irrigation (Percent_CutBack) use accounted for $45 \%$ of irrigated land, end block irrigation (Percent_EndBlock) use accounted for $43 \%$ of irrigated land, and deep tillage (Percent_DeepTillage) accounted for $36 \%$ of irrigated land. The irrigation practice with the smallest percentage of the irrigated land was warped surface leveling (Percent_WarpedSurface) and accounted for $22 \%$.

This study's explanatory variables are divided into three categories in Table 2: Farm and Irrigation Characteristics, Socioeconomic Characteristics, and Peer Network. Land use and Irrigation Characteristics include binary variables that indicate the kind of irrigated crop grown by a farmer. For example, $80 \%$ have irrigated soybeans (IrrSoy). Additional binary variables describe the type of irrigation practices used on the farms. Only $3 \%$ use Et or atmometers to schedule irrigation times (ETAtmometer). Tail-water recovery systems 
(TWR) are used on $45 \%$ of farms according to the participating producers, and surge irrigation (Surge) is only used by 16\%. The third set of binary variables relates to the county of the respondent. The Delta was broken into five categories to group the farms in similar locations. There are $31 \%$ of respondents that lived in a county in Crowley's Ridge (Ridge), and $7 \%$ lived in a county in the South Delta and not in the previously described areas (SD). Another set of binary variables relate to a farmer's participation in conservation programs. The percentage of farmers participating in a conservation reserve program (PartCRP) and the environmental quality incentives program (PartEQIP) is $43 \%$ and $45 \%$, respectively. The final set of binary variables relate to why a producer decides to use or decides not to use precision leveling. For example, $19 \%$ of producers use precision grade leveling to make irrigation more profitable (PrecisionLevelProfit).

Table 1. Dependent variables for participation equation and outcome equation.

\begin{tabular}{|c|c|c|c|c|c|}
\hline Variable & Definition & Mean & Std Dev & 10th Percentile & 90th Percentile \\
\hline Border & $=1$ if used border irrigation & 0.13 & 0.333 & 0 & 1 \\
\hline PrecisionGrade & $=1$ if used precision grade $/$ constant slope & 0.84 & 0.369 & 0 & 1 \\
\hline WarpedSurface & $=1$ if used warped surface/optisurface & 0.25 & 0.436 & 0 & 1 \\
\hline EndBlock & $=1$ if used end-blocking & 0.25 & 0.433 & 0 & 1 \\
\hline CutBack & $=1$ if used cutback irrigation & 0.08 & 0.270 & 0 & 1 \\
\hline DeepTillage & $=1$ if used deep tillage & 0.35 & 0.479 & 0 & 1 \\
\hline Percent_Border & $\begin{array}{l}\text { Percent of irrigated acres using border } \\
\text { irrigation if border }=1\end{array}$ & 53.16 & 40.85 & 0.4 & 100 \\
\hline $\begin{array}{l}\text { Percent_Precision } \\
\text { Grade }\end{array}$ & $\begin{array}{l}\text { Percent of irrigated acres using precision } \\
\text { grade/constant slope if precision grade }=1\end{array}$ & 56.69 & 36.69 & 1.08 & 100 \\
\hline Percent_Warped Surface & $\begin{array}{l}\text { Percent of irrigated acres using warped } \\
\text { surface } / \text { optisurface if warped surface }=1\end{array}$ & 22.18 & 21.29 & 1.28 & 100 \\
\hline Percent_EndBlock & $\begin{array}{l}\text { Percent of irrigated acres using } \\
\text { end-blocking if end block }=1\end{array}$ & 43.01 & 30.21 & 2.27 & 100 \\
\hline Percent_CutBack & $\begin{array}{c}\text { Percent of irrigated acres using cutback } \\
\text { irrigation if cutback }=1\end{array}$ & 45.35 & 29.69 & 3.33 & 100 \\
\hline $\begin{array}{l}\text { Percent_Deep } \\
\text { Tillage }\end{array}$ & $\begin{array}{c}\text { Percent of irrigated acres using deep tillage } \\
\text { if deep tillage }=1\end{array}$ & 36.68 & 25.97 & 2.94 & 100 \\
\hline
\end{tabular}

Table 2. Explanatory variables for irrigation technology modeling.

\begin{tabular}{llr}
\hline Farm and Irrigation Characteristics & \\
\hline Variable & Definition & Proportion \\
\hline IrrRice & $=1$ if grew rice & 0.59 \\
IrrSoy & $=1$ if grew irrigated soy \\
FlowMeter & $=1$ if owned any flow meters \\
SoilSensor & $=1$ if used soil moisture to schedule irrigation on farm \\
ETAtmometer & $=1$ if used ET or atmometer to schedule irrigation times & 0.80 \\
ComputerizedScheduling & $=1$ if used computerized scheduling to schedule irrigation \\
DieselPump & $=1$ if used diesel pump on farm \\
Ridge & $=1$ if county is in Crowley's Ridge \\
River & $=1$ if county is along Mississippi River \\
Grand Prairie & $=1$ if county is in the Grand Prairie \\
ND & $=1$ if county is in the North Delta and not others \\
SD & $=1$ if county is in the South Delta and not others \\
TWR & $=1$ if used tail-water recovery system on farm \\
TaxCredStorage & $=1$ if payment for tail-water recovery system or reservoir was state tax \\
PartCRP & credit program & 0.10 \\
PartEQIP & $=1$ if participated in conservation reserve program \\
PartRegCon & $=1$ if participated in environmental quality incentives program \\
PartOther & $=1$ if participated in regional conservation partnership program & 0.03 \\
\hline
\end{tabular}


Table 2. Cont.

\begin{tabular}{|c|c|c|c|}
\hline \multicolumn{4}{|c|}{ Farm and Irrigation Characteristics } \\
\hline Variable & Definition & & Proportion \\
\hline ComputerizedHole & $=1$ if used computerized hole selection & & 0.33 \\
\hline Surge & $=1$ if used surge irrigation & & 0.16 \\
\hline PrecisionLevelProfit & $=1$ if used precision leveling to make irrigation more profitable & & 0.19 \\
\hline NoPrecisionLevelCost & $=1$ if precision leveling is not used, because the cost is too high & & 0.06 \\
\hline \multirow[t]{2}{*}{ PivotRow } & $=1$ if used center pivot irrigation for row crops & & 0.38 \\
\hline & & Mean & Std Dev \\
\hline IrrCottonAcres & Number of irrigated cotton acres (in hundreds) & 112.88 & 458.04 \\
\hline IrrRiceAcres & Number of irrigated rice acres (in hundreds) & 654.79 & 979.26 \\
\hline YieldCorn & Expected yield of corn (in tens of bushels per acre) & 85.85 & 95.82 \\
\hline PrecisionGrade & Number of irrigated acres using precision grade system & 1047.22 & 1537.40 \\
\hline ZeroGrade & Number of irrigated acres using zero grade system & 49.07 & 156.62 \\
\hline EndBlock & Number of irrigated acres using end block irrigation & 285.52 & 786.39 \\
\hline Multi-Inlet & $\begin{array}{l}\text { Number of irrigated acres that are contour levee fields using multiple inlet } \\
\text { irrigation }\end{array}$ & 157.02 & 422.22 \\
\hline AltWetDry & $\begin{array}{l}\text { Number of irrigated rice acres managed under alternative wetting and } \\
\text { drying }\end{array}$ & 54.10 & 343.57 \\
\hline WarpedSurface & Number of irrigated acres using warped surface leveling & 186.89 & 769.78 \\
\hline $\mathrm{PH}>6.0$ & $\begin{array}{l}\text { Percent of land in the county of the producer's residence with a } \mathrm{pH} \text { greater } \\
\text { than } 6.0\end{array}$ & 23.16 & 16.72 \\
\hline AWS & Root zone between 0 to 59 inches of available water storage (in) & 9.11 & 1.19 \\
\hline РPТ2013 & Growing season precipitation in 2013 (in) & 27.11 & 4.02 \\
\hline РPT2014 & Growing season precipitation in 2014 (in) & 28.07 & 2.50 \\
\hline PPT2015 & Growing season precipitation in 2015 (in) & 26.71 & 4.49 \\
\hline GDD2013 & Degree days between 50 and 89 Fahrenheit in 2013 (degrees*days) & 2396.22 & 101.18 \\
\hline GDD2014 & Degree days between 50 and 89 Fahrenheit in 2014 (degrees*days) & 2362.51 & 84.57 \\
\hline Clay & $\begin{array}{l}\text { Percent of land in the county of the producer's residence with a clay } \\
\text { component in the soil }\end{array}$ & 14.71 & 16.61 \\
\hline Loam & $\begin{array}{l}\text { Percent of land in the county of the producer's residence with a loam } \\
\text { component in the soil }\end{array}$ & 6.56 & 6.09 \\
\hline Silt & $\begin{array}{l}\text { Percent of land in the county of the producer's residence with a silt } \\
\text { component in the soil }\end{array}$ & 63.36 & 17.77 \\
\hline Sand & $\begin{array}{l}\text { Percent of land in the county of the producer's residence with a sand } \\
\text { component in the soil }\end{array}$ & 9.41 & 8.39 \\
\hline OpenWater & $\begin{array}{l}\text { Miles of flow length through streams, rivers, lakes, and any other open } \\
\text { water in the county of the producer's residence }\end{array}$ & 29.30 & 15.88 \\
\hline BarrierPipe & $\begin{array}{l}\text { Miles of pipeline that connect waterbodies separated by dams, weirs, and } \\
\text { other artificial barriers in the county of the producer's residence }\end{array}$ & 0.07 & 0.11 \\
\hline CanalDitch & Miles of canals and ditches in the county of the producer's residence & 21.28 & 19.50 \\
\hline AqueductPipe & $\begin{array}{l}\text { Miles of aqueduct and other closed conduits with pumps, valves, and } \\
\text { control devices in the county of the producer's residence }\end{array}$ & 0.01 & 0.04 \\
\hline \multirow{2}{*}{$\begin{array}{l}\text { StreamRiver } \\
\text { Socioeconomic characteristics }\end{array}$} & Miles of streams and rivers in the county of the producer's residence & 85.69 & 44.06 \\
\hline & & \multicolumn{2}{|c|}{ Proportion } \\
\hline AgEdu & $=1$ if formal education related to agriculture & & 0.56 \\
\hline Bach & $=1$ if completed Bachelor's degree & & 0.42 \\
\hline AdvEdu & $=1$ if completed education beyond a Bachelor's degree & & 0.09 \\
\hline IncHigh & $=1$ if household income greater than USD $200 \mathrm{~K}$ & & 0.15 \\
\hline IncNA & $=1$ if household income not available & & 0.23 \\
\hline
\end{tabular}


Table 2. Cont.

\begin{tabular}{|c|c|c|}
\hline \multicolumn{3}{|l|}{ Peer Network } \\
\hline Variable & Definition & Proportion \\
\hline PeerPivot & $=1$ if peers used center pivot & 0.67 \\
\hline PeerTWR & $=1$ if peers used tail-water recovery system & 0.66 \\
\hline PeerRes & $=1$ if peers used reservoir storage & 0.60 \\
\hline PeerCHS & $=1$ if peers used computerized hole selection & 0.52 \\
\hline PeerSurge & $=1$ if peers used surge irrigation & 0.34 \\
\hline PeerFlowMeter & $=1$ if peers used flowmeters on the wells & 0.62 \\
\hline PeerPLevel & $=1$ if peers used precision leveling & 0.87 \\
\hline PeerZeroGrade & $=1$ if peers used zero grade leveling & 0.71 \\
\hline PeerEndBlock & $\begin{array}{l}=1 \text { if peers used alternate end-blocking, cutback irrigation, or furrow } \\
\text { diking in irrigation }\end{array}$ & 0.50 \\
\hline PeerScheduling & $\begin{array}{l}=1 \text { if peers used irrigation scheduling such as soil moisture sensors, ET, } \\
\text { and atmometer }\end{array}$ & 0.49 \\
\hline PeerMulti-Inlet & $=1$ if peers used multiple-inlet rice irrigation & 0.65 \\
\hline PeerAltWetDry & $=1$ if peers used wetting and drying for rice irrigation & 0.33 \\
\hline PeerPivot*Ridge & $=1$ if peers used center pivot and located on Crowley's Ridge & 0.22 \\
\hline PeerTWR*River & $\begin{array}{l}=1 \text { if peers used tail-water recovery system and located along the } \\
\text { Mississippi River }\end{array}$ & 0.10 \\
\hline PeerTWR*ND & $=1$ if peers used tail-water recovery system and located in the North Delta & 0.12 \\
\hline PeerRes*GP & $=1$ if peers used reservoir storage and located in the Grand Prairie & 0.17 \\
\hline PeerCHS*SD & $=1$ if peers used computerized hole selection and located in the South Delta & 0.03 \\
\hline PeerCHS*Ridge & $\begin{array}{l}=1 \text { if peers used computerized hole selection and located along Crowley's } \\
\text { Ridge }\end{array}$ & 0.16 \\
\hline PeerCHS*CRP & $\begin{array}{l}=1 \text { if peers used computerized hole selection and participated in } \\
\text { conservation reserve program }\end{array}$ & 0.25 \\
\hline PeerSurge*Fed & $\begin{array}{l}=1 \text { if peers used surge irrigation and the irrigator raised money for } \\
\text { tail-water recovery or reservoir through a federal cost-share program }\end{array}$ & 0.08 \\
\hline PeerSurge ${ }^{*} \mathrm{CHS}$ & $=1$ if peers used surge irrigation and computerized hole selection & 0.15 \\
\hline PeerSurge*RegCon & $\begin{array}{l}=1 \text { if peers used surge irrigation and participated in regional conservation } \\
\text { partnership program }\end{array}$ & 0.07 \\
\hline PeerFlowMeter*Ridge & $=1$ if peers used flowmeter and located on Crowley's Ridge & 0.17 \\
\hline PeerFlowMeter*GP & $=1$ if peers used flowmeter and located in the Grand Prairie & 0.16 \\
\hline PeerFlowMeter*Fed & $\begin{array}{l}=1 \text { if peers used flowmeter and the irrigator raised money for tail-water } \\
\text { recovery or reservoir through a federal cost-share program }\end{array}$ & 0.18 \\
\hline PeerFlowMeter*RegCon & $\begin{array}{l}=1 \text { if peers used flowmeter and participated in regional conservation } \\
\text { partnership program }\end{array}$ & 0.10 \\
\hline PeerEndBlock*PartOther & $\begin{array}{l}=1 \text { if peers used end-blocking and participated in other conservation } \\
\text { program }\end{array}$ & 0.15 \\
\hline PeerEndBlock*RegCon & $\begin{array}{l}=1 \text { if peers used end-blocking and participated in regional conservation } \\
\text { partnership program }\end{array}$ & 0.09 \\
\hline PeerScheduling*Ridge & $=1$ if peers used irrigation scheduling and located on Crowley's Ridge & 0.15 \\
\hline PeerScheduling*SD & $=1$ if peers used irrigation scheduling and located in the South Delta & 0.04 \\
\hline PeerScheduling*ND & $=1$ if peers used irrigation scheduling and located in the North Delta & 0.06 \\
\hline PeerScheduling*CRP & $\begin{array}{l}=1 \text { if peers used irrigation scheduling and participated in conservation } \\
\text { reserves program }\end{array}$ & 0.26 \\
\hline PeerMult-Inlet*Ridge & $\begin{array}{l}=1 \text { if peers used multiple-inlet rice irrigation and located on Crowley's } \\
\text { Ridge }\end{array}$ & 0.18 \\
\hline PeerMult-Inlet*GP & $\begin{array}{l}=1 \text { if peers used multiple-inlet rice irrigation and located in the Grand } \\
\text { Prairie }\end{array}$ & 0.16 \\
\hline PeerMult-Inlet*ND & $=1$ if peers used multiple-inlet rice irrigation and located in the North Delta & 0.15 \\
\hline PeerMult-Inlet*RegCon & $\begin{array}{l}=1 \text { if peers used multiple-inlet rice irrigation and participated in regional } \\
\text { conservation partnership program }\end{array}$ & 0.10 \\
\hline PeerMult-Inlet*PartOther & $\begin{array}{l}=1 \text { if peers used multiple-inlet rice irrigation and participated in other } \\
\text { conservation programs }\end{array}$ & 0.17 \\
\hline PeerMult-Inlet*Fed & $\begin{array}{l}=1 \text { if peers used multiple-inlet rice irrigation and the irrigator raised money } \\
\text { for tail-water recovery or reservoir through a federal cost-share program }\end{array}$ & 0.18 \\
\hline PeerAltWetDry*ND & $\begin{array}{l}=1 \text { if peers used wetting and drying for rice irrigation and located in the } \\
\text { North Delta }\end{array}$ & 0.04 \\
\hline
\end{tabular}


Table 2. Cont.

\begin{tabular}{lll}
\hline Peer Network & Definition & Proportion \\
\hline Variable & $\begin{array}{l}=1 \text { if peers used wetting and drying for rice irrigation and located in the } \\
\text { South Delta } \\
=1 \text { if peers used wetting and drying for rice irrigation and participated in } \\
\text { PeerAltWetDry*SD }\end{array}$ & $\begin{array}{l}\text { other conservation programs } \\
=1 \text { if peers used wetting and drying for rice irrigation and the irrigator } \\
\text { Paised money for tail-water recovery or reservoir through a federal } \\
\text { cost-share program }\end{array}$ \\
\hline
\end{tabular}

The continuous variables in this category relate to the acreage devoted to each crop and the expected yield (in hundreds of bushels) from the crops. The total average acreage under irrigation (IrrAcres) is 2325. The average expected yield of corn (YieldCorn) is 859 bushels per acre. There are also continuous variables in this section that describe the number of irrigated acres using different irrigation techniques. The number of irrigated acres using end block irrigation (EndBlock) was 285 acres, the number of irrigated acres that are contour levee fields using multiple inlet irrigation (Multi-Inlet) was 157, and the average use of warped surface leveling (WarpedSurface) was 186 acres.

The last subsection of continuous variables is the physical characteristics. The prism climate group states that 2013 had 27.11 inches of growing season precipitation (PPT2013), yet 2015 only had 26.71 inches of growing season precipitation (PPT2015) [24]. It was also reported that there were 2396 degree days between 50 and 89 Fahrenheit in 2013 (GDD2013), which is degrees*days [24]. The SSURGO database indicates the percentage of land in the county of the producer's residence that has a clay (Clay), loam (Loam), silt (Silt), and sand (Sand) [23]. According to the national hydrology dataset, a county has an average of 29 miles of flow length through streams, rivers, lakes, and any other open water (OpenWater) [25]. We also collected three variables to gage the level of irrigation infrastructure in a county (BarrierPipe, CanalDitch, and AqueductPipe) from the national hydrology dataset.

In the Socioeconomic Characteristics category, the highest education attained by producers in our sample varies considerably. A total of $56 \%$ reported having an agricultural education background (AgEdu), 42\% reported earning a bachelor's degree (Bach), and 9\% reported earning higher than a bachelor's degree (AdvEdu). In addition, 15\% had an income higher than USD $200 \mathrm{~K}$ (IncHigh), and 23\% did not report any income (IncNA).

The social learning category is primarily on peer networks and information sharing. Binary variables are used to solicit a response from this question: "Please tell me if one or more of your close family members, friends, or neighbor producers has used this practice in the past 10 years?" Here, 66\% know someone who has a tail-water recovery system (PeerTWR), and 60\% know someone who has reservoir storage (PeerRes). Moreover, 52\% know someone who uses computerized hole selection (PeerCHS), 62\% know someone who owns and uses flow meters (PeerFlowMeter), 50\% know someone who uses end-blocking, and cutback irrigation, or furrow diking in irrigation (PeerEndBlock). A total of $49 \%$ know someone who uses irrigation scheduling (PeerSchedule), and 33\% know someone who uses alternate wetting and drying for rice irrigation (PeerAltWetDry). These responses do not imply respondents use any of these aforementioned practices but rather sought to determine if there is contact with extension offices they have, and ultimately how belonging to these different peer networks affects the adoption of irrigation measurement tools.

The final set of social learning variables are interaction variables to examine the relationship between participating in a conservation program, using practices promoted by extension personnel, or geographic location with a farmer's peer network. Twelve percent of producers live in the North Delta and know someone using tail-water recovery $($ PeerTWR $\times$ ND). Three percent of producers use computerized hole selection and live in the South Delta (PeerCHS $\times$ SD), while $25 \%$ of producers use computerized hole selection 
and participate in conservation reserve programs $($ PeerCHS $\times \mathrm{CRP})$. Producers with peers using surge irrigation and the irrigator raised money for tail-water recovery or reservoirs through a federal cost-share program for on-farm reservoirs (PeerSurge $\times$ Fed) and this is $8 \%$ of the sample, and $7 \%$ have peers using surge irrigation while participating in a regional conservation partnership program (PeerSurge $\times$ RegCon). Seventeen percent of producers have peers using flow meters and live on Crowley's Ridge (PeerFlowmeter $\times$ Ridge), while $16 \%$ have peers using flow meters and live in the Grand Prairie (PeerFlowmeter $\times$ GP). Eighteen percent of the producers have peers that use flow meters and participation in a federal cost-share program for on-farm reservoirs (PeerFlowmeter $\times$ Fed).

Fifteen percent participate in another conservation reserve program and know someone using end block irrigation (PeerEndBlock $\times$ PartOther), but $9 \%$ participate in a regional conservation partnership program and know someone using end block irrigation (PeerEndBlock $\times$ RegCon). Fifteen percent live along Crowley's Ridge and know someone using irrigation scheduling (PeerScheduling $\times$ Ridge), and $26 \%$ participate in the conservation reserves program and have peers that use irrigation scheduling (PeerScheduling $\times C R P$ ). Producers that have peers that use multiple inlet irrigation rice irrigation and live in the Grand Prairie (PeerMultiInlet $\times$ GP) are $16 \%$ of the sample. Four percent of the producers have peers using wetting and drying for rice irrigation and live in the North Delta (PeerAltWetDry $\times$ ND), and $8 \%$ participate in a federal cost-share program for on-farm reservoirs (PeerAltWetDry $\times$ Fed).

\subsection{Statistical Methods}

A bivariate sample selection model was used to find the factors correlated between using irrigation techniques and explaining the share of acres using each technique. This model allows the maximum likelihood of each independent variable having an impact on the dependent variables. It also better explains the influence that producers' choices have on the use and share of acres under an irrigation technique. Each bivariate sample selection model is composed of participation and an outcome equation. The participation equation's dependent variables are binary to specify the use of an irrigation technique. The outcome equation's dependent variables are the share of acres of each technique if that land is used.

The dependent variable in the participation equation, $y_{1}$, is an incompletely observed value of a latent dependent variable $y_{1}^{*}$, where the observation rule is

$$
y_{1}= \begin{cases}1 & \text { if } y_{1}^{*}>0 \\ 0 & \text { if } y_{1}^{*} \leq 0\end{cases}
$$

and a resultant outcome equation such that

$$
y_{2}= \begin{cases}y_{2}^{*} & \text { if } y_{1}^{*}>0 \\ - & \text { if } y_{1}^{*} \leq 0\end{cases}
$$

This model indicates that $y_{2}$ is observed when $y_{1}^{*}>0$, and $y_{2}$ does not take on a value when $y_{1}^{*} \leq 0$. The latent variables $y_{1}^{*}$ and $y_{2}^{*}$ specify that the use and percentage of land from each technique are not observed for the population as a whole. This then specifies a linear model with additive errors for the latent variables, so

$$
\begin{aligned}
& y_{1}^{*}=x_{1}^{\prime} \beta_{1}+\varepsilon_{1}, \\
& y_{2}^{*}=x_{2}^{\prime} \beta_{2}+\varepsilon_{2} .
\end{aligned}
$$

Problems from this will arise in estimating $\beta_{2}$ if $\varepsilon_{1}$ and $\varepsilon_{2}$ are correlated.

We estimate using maximum likelihood, which is asymptotically efficient, and using the additional assumption that the correlated errors are joint-normally distributed and homoscedastic with

$$
\left[\frac{\varepsilon_{1}}{\varepsilon_{2}}\right] \sim \aleph\left[\left[\frac{0}{0}\right],\left[\begin{array}{cc}
1 & \sigma_{12} \\
\sigma_{12} & \sigma_{2}^{2}
\end{array}\right]\right] .
$$


The bivariate sample selection model uses the likelihood function

$$
L=\prod_{i=1}^{n}\left\{\operatorname{Pr}\left[y_{1 i}^{*} \leq 0\right]\right\}^{1-y_{1 i}}\left\{f\left(y_{2 i} \mid y_{1 i}^{*}>0\right) \times \operatorname{Pr}\left[y_{1 i}^{*}>0\right]\right\}^{y_{1 i}}
$$

where the first term is the participation equation when $y_{1 i}^{*}=0$, and the second term is thus the outcome equation when $y_{1 i}^{*}>0$.

The participation equation's marginal effects show the change in the probability of participation in response to a one-unit increase in the explanatory variables. The marginal effects in the outcome equation are the expected change in $y_{2}$ for a change in an explanatory variable, dependent on participation and use of the irrigation technique. If an independent variable appears only in the outcome equation, its marginal effect is equal to its coefficient. If the independent variable appears only in the participation equation, a change in the explanatory variable in the participation equation affects the expected value of the error term in the participation equation, which, through correlation of the error terms in both equations, leads to an expected change in $y_{2}$. If the independent variable appears in both the participation and outcome equations, there is an expected change in $y_{2}$ from a direct effect from the explanatory variable in the outcome equation and an indirect effect from the explanatory variable in the participation equation because of the correlation of the error terms in both equations. The maximum likelihood estimation occurs through the models available in Stata ${ }^{\circledR}$ version 13.1 .

\section{Results}

Marginal effects for explaining whether a producer uses a particular irrigation practice appear in Tables 3 and 4. The marginal effects for the explanatory variables representing the irrigation practices in use by peers are shown in Table 3. All the other predictors for the use of an irrigation practice appear in Table 4 . The use of border irrigation is influenced by whether an irrigator's peers use computerized hole selection, surge irrigation, and zero grade leveling. A producer with a peer that uses computerized hole selection (PeerCHS) has a likelihood of using border irrigation that decreases by $14.3 \%$. If a peer uses surge irrigation and participates in a federal cost-share program for on-farm reservoirs (PeerSurge $\times$ Fed), the likelihood of border irrigation use increases by $22.7 \%$. The $22.7 \%$ increase is the addition of the $2.5 \%$ increase and the $20.2 \%$ increase if the irrigator raised money for tail-water recovery or reservoirs through a federal cost-share program (PeerSurge $\times$ Fed). Having a peer that uses zero grade irrigation increases the chance of using border irrigation by 7.7\% (PeerZeroGrade).

The use of precision grade leveling is primarily influenced by peers that use pivot irrigation. If a producer has a peer that uses pivot irrigation, precision grade leveling increases by a not statistically significant $2.2 \%$. However, if that producer lives along Crowley's Ridge, the likelihood decreases by a statistically significant $11.0 \%(2.2 \%+-13.2 \%)$ (PeerPivot $\times$ Ridge). Warped surface leveling correlates with several peer variables. If a producer knows someone that uses flow meters (PeerFlowmeter), the likelihood that they will use warped surface leveling increases by about $10 \%$. On the other hand, if a producer knows someone that uses multiple inlet irrigation (PeerMulti-Inlet), the likelihood of using warped surface irrigation decreases by $37.4 \%$. This decrease in use holds for producers that live along Crowley's Ridge, but not for producers who live in the Grand Prairie where the likelihood increases by $13.4 \%(-37.4 \%+50.8 \%)$ (PeerMulti-Inlet $\times$ GP) or the North Delta where the likelihood increases by $12.8 \%(-37.4 \%+50.2 \%)$ (PeerMulti-Inlet*ND). Knowing someone that uses alternating wetting and drying (PeerAltWetDry) as an irrigation practice decreases the likelihood of using warped surface leveling by $14.3 \%$, unless they live in the South Delta (PeerAltWetDry $\times$ SD), in which case the use of warped surface leveling increases by $19.1 \%(-14.3 \%+33.4 \%)$.

A producer is $41.3 \%$ more likely to use end block irrigation if they know someone who also uses end-blocking irrigation (PeerEndBlock). A producer that lives along Crowley's Ridge and has a peer that uses flow meters (PeerFlowMeter $\times$ Ridge) is $34.0 \%$ 
$(-2.2 \%+-31.8 \%)$ less likely to use end-blocking irrigation on their farm. Having a peer that uses multiple inlet irrigation (PeerMulti-Inlet) decreases the use of end-blocking irrigation by $20.4 \%$. This is reinforced by producers who also participate in a federal cost-share program for on-farm reservoirs because the likelihood of end block irrigation use is reduced by $63.1 \%(-20.4 \%+-42.7 \%)$ (PeerMulti-Inlet $\times$ Fed).

Table 3. Marginal effects for the peer network variables to explain the percent use of an irrigation practice.

\begin{tabular}{|c|c|c|c|c|c|}
\hline Variable & $\begin{array}{c}\text { Border } \\
\text { Irrigation }\end{array}$ & $\begin{array}{l}\text { Precision Grade } \\
\text { Leveling }\end{array}$ & $\begin{array}{l}\text { Warped Surface } \\
\text { Leveling }\end{array}$ & $\begin{array}{l}\text { End Block } \\
\text { Irrigation }\end{array}$ & Deep Tillage \\
\hline PeerPivot & & $0.022(0.36)$ & & & \\
\hline PeerCHS & $-0.143(-3.28)^{a}$ & & & & $0.244(1.83)^{\mathrm{c}}$ \\
\hline PeerSurge & $0.025(0.62)$ & & & & \\
\hline PeerFlowMeter & & & $0.112(1.97)^{b}$ & $-0.022(-0.27)$ & \\
\hline PeerZeroGrade & $0.077(1.75)^{\mathrm{c}}$ & & & & \\
\hline PeerEndBlock & & & & $0.413(3.82)^{\mathrm{a}}$ & \\
\hline PeerScheduling & & & & & $0.006(0.16)$ \\
\hline PeerMulti-Inlet & & & $-0.374(-1.95)^{b}$ & $-0.204(-2.20)^{b}$ & \\
\hline PeerAltWetDry & & & $-0.143(-2.37)^{a}$ & & \\
\hline PeerPivot $\times$ Ridge & & $-0.132(-2.01)^{b}$ & & & \\
\hline PeerCHS $\times$ Ridge & & & & & $0.213(1.66)^{c}$ \\
\hline PeerCHS $\times$ SD & & & & & $-0.999(-2.41)^{\mathrm{a}}$ \\
\hline PeerCHS $\times$ CRP & & & & & $-0.373(-2.46)^{a}$ \\
\hline PeerSurge $\times$ Fed & $0.202(2.58)^{\mathrm{a}}$ & & & & \\
\hline PeerFlowMeter $\times$ Ridge & & & & $-0.318(-2.80)^{\mathrm{a}}$ & \\
\hline PeerScheduling $\times$ ND & & & & & $-0.522(2.32)^{b}$ \\
\hline PeerScheduling $\times$ SD & & & & & $-0.738(1.90)^{b}$ \\
\hline PeerScheduling $\times \mathrm{CRP}$ & & & & & $0.419(2.78)^{\mathrm{a}}$ \\
\hline PeerMult-Inlet $\times$ Ridge & & & $0.346(1.69)^{c}$ & & \\
\hline PeerMult-Inlet $\times$ GP & & & $0.508(2.39)^{\mathrm{a}}$ & & \\
\hline PeerMult-Inlet $\times$ ND & & & $0.502(2.32)^{b}$ & & \\
\hline PeerMult-Inlet $\times$ Fed & & & & $-0.427(-1.71)^{\mathrm{c}}$ & \\
\hline PeerAltWetDry ×SD & & & $0.334(1.66)^{c}$ & & \\
\hline \multicolumn{6}{|l|}{$\begin{array}{c}\text { PeerAltWetDry } \times \text { Part } \\
\text { Other }\end{array}$} \\
\hline Pseudo $R^{2}$ & 0.222 & 0.218 & 0.286 & 0.467 & 0.251 \\
\hline $\begin{array}{l}\text { Number of } \\
\text { observation }\end{array}$ & 229 & 221 & 229 & 197 & 221 \\
\hline
\end{tabular}


Table 4. Marginal effects for the peer network variables to explain the percent use of an irrigation practice.

\begin{tabular}{|c|c|c|c|c|c|}
\hline Variable & $\begin{array}{c}\text { Border } \\
\text { Irrigation }\end{array}$ & $\begin{array}{l}\text { Precision Grade } \\
\text { Leveling }\end{array}$ & $\begin{array}{l}\text { Warped Surface } \\
\text { Leveling }\end{array}$ & $\begin{array}{l}\text { End Block } \\
\text { Irrigation }\end{array}$ & Deep Tillage \\
\hline IrrRice & & & $0.174(2.64)^{\mathrm{a}}$ & & \\
\hline IrrSoy & $-0.084(-2.07)^{b}$ & & $0.374(3.75)^{a}$ & & $0.365(2.87)^{a}$ \\
\hline \multicolumn{6}{|l|}{ CoverCrop } \\
\hline Advanced Education & & & & & $-0.314(-2.02)^{b}$ \\
\hline Ag. Education & & & & & $-0.207(-2.67)^{a}$ \\
\hline \multicolumn{6}{|l|}{ IncHigh } \\
\hline SoilSensor & & & $-0.252(-2.27)^{b}$ & & $-0.289(-1.99)^{b}$ \\
\hline MultipleInlet & & & $0.000(1.88)^{c}$ & & \\
\hline ETAtmometer & & & $0.482(2.68)^{\mathrm{a}}$ & & $0.488(2.15)^{\mathrm{b}}$ \\
\hline \multicolumn{6}{|l|}{ ComputerSchedule } \\
\hline River & $-0.166(-2.56)^{b}$ & & & & \\
\hline \multicolumn{6}{|l|}{ ND } \\
\hline SD & & & $0.519(2.44)^{\mathrm{a}}$ & & \\
\hline TWR & & & & $0.178(2.29)^{b}$ & \\
\hline \multicolumn{6}{|l|}{ PivotRow } \\
\hline YieldCorn & & & & $0.001(2.46)^{a}$ & $0.001(2.79)^{\mathrm{a}}$ \\
\hline PrecisionLevelProfit & & & & & $0.292(2.43)^{\mathrm{a}}$ \\
\hline ZeroGrade & $0.000(2.17)^{b}$ & & & & \\
\hline PartOther & & & $0.075(1.73)^{\mathrm{c}}$ & & \\
\hline AWS & & $0.027(2.13)^{b}$ & & & \\
\hline \multicolumn{6}{|l|}{ Clay } \\
\hline GDD 2013 & & $-0.001(-2.24)^{b}$ & & & $0.002(3.54)^{a}$ \\
\hline PPT 2014 & & & $-0.031(-2.58)^{a}$ & $0.032(2.03)^{b}$ & \\
\hline PPT 2015 & & & $-0.017(-1.83)^{\mathrm{c}}$ & & \\
\hline StreamRiver & & & $-0.001(-1.68)^{\mathrm{c}}$ & & \\
\hline Pseudo $\mathrm{R}^{2}$ & 0.222 & 0.218 & 0.286 & 0.467 & 0.251 \\
\hline Number of observation & 229 & 221 & 229 & 197 & 221 \\
\hline
\end{tabular}

${ }^{a}-1 \%, b-5 \%,{ }^{c}-10 \%$ significance. $Z$ statistics from the probit model estimates in parentheses.

If a producer lives in the South Delta or participates in the conservation reserve program and has a peer that utilizes computerized hole selection (PeerCHS $\times$ SD and PeerCHS $\times$ CRP), they are $75.5 \%(24.4+-99.9 \%)$ and $12.9 \%(24.4+-37.3 \%)$ less likely to use deep tillage, respectively. Others that have peers using computerized hole selection are $24.4 \%$ more likely to use deep tillage (PeerCHS). Living along Crowley's Ridge and having a peer that uses computerized hole selection increases the likelihood of using deep tillage by $45.7 \%(24.4 \%+21.3 \%)$. Having a peer that uses irrigation scheduling (PeerScheduling) decreases the likelihood of deep tillage by $0.6 \%$; however, living in the North Delta or South Delta and knowing someone that schedules irrigation (PeerScheduling $\times$ ND and PeerScheduling $\times$ SD) decrease the likelihood of using deep tillage by $52 \%$ and $78 \%$, respectively. In addition, having a peer that uses scheduling and participates in a conservation reserve program (PeerScheduling $\times \mathrm{CRP})$ is $42.5 \%(0.6 \%+41.9 \%)$ more likely to use deep tillage on their farm. 
Table 4 shows the marginal effects for the explanatory farm, irrigation, and socioeconomic variables that influence the irrigation technique choice. For example, producers that live along the Mississippi River (River) are $16.6 \%$ less likely to use border irrigation. In addition, having irrigated soybeans (IrrSoy) reduces the likelihood of using border irrigation by $8.4 \%$. The singular socioeconomic variable that affected the use of precision grade leveling, with any magnitude, is having a root zone between 0 to 59 inches with available water storage (AWS). It reduced the likelihood of using precision grade leveling by $2.7 \%$. The number of degree days between 50 and 89 Fahrenheit in 2013 (GDD2013), which is degrees*days, reduces the likelihood of using precision grade leveling by $0.1 \%$. The likelihood that warped surface leveling use increases by at least $37 \%$ if a producer lives in the South Delta region (SD), has irrigated soybeans (IrrSoy), or utilizes atmometers (ETAmometer). If a producer has irrigated rice (IrrRice) or participates in a conservation program other than a prominent federal cost-share program (PartOther), then the likelihood of using warped surface leveling increases. The only variable that reduces the use of warped surface leveling is soil sensors (SoilSensor). If a producer uses soil sensors, they are $25.2 \%$ less likely to use warped surface leveling.

Only tail-water recovery systems seem to influence the use of end block irrigation with any magnitude. The use of tail-water recovery increases the chance of using end block irrigation by $17.8 \%$ (TWR). The expected yield of corn (YieldCorn) and the growing season precipitation of 2014 (PPT2014) increases the chance of using end block irrigation by $0.1 \%$. Producers are less likely to use deep tillage on their farm if they have formal agricultural education or have an advanced degree (AgEdu and AdvEdu). If a producer uses soil sensors, then they are $28.9 \%$ less likely to utilize deep tillage. When a producer uses atmometers or has irrigated soybeans, they are more likely to use deep tillage. Using precision leveling because it is more profitable also increases the likelihood of using deep tillage on their farm by $29.2 \%$. The number of degree days between 10 and 32 Celsius in 2013 , which is degrees $\times$ days, increases the likelihood of using deep tillage by $0.2 \%$.

Marginal effects for explaining the share of acres that utilize each practice appear in Tables 5 and 6 . Previously, we considered why producers use particular practices, but now, conditional on the decision to use the practice, we are looking at the percent of irrigated acres in each practice. The marginal effects in Table 5 are for the explanatory variables that relate to the producer's peer network of fellow irrigators.

If a producer knows someone that uses flow meters (PeerFlowMeter), the share of irrigated land in border irrigation decreases 0.136. Having a peer that uses flow meters and participates in a federal cost-share program for on-farm reservoirs is estimated to use a substantially larger share of border irrigation, $0.346(-0.136+0.482)$ to be exact (PeerFlowmeter $\times$ Fed). Producers living in the Grand Prairie and who know someone who uses flow meters (PeerFlowmeter $\times$ GP) have $0.815(-0.136+-0.679)$ fewer shares of irrigated land that utilizes border irrigation. The share of irrigated land that uses precision grade leveling also decreases if a producer has a peer that uses flow meters (PeerFlowmeter). Knowing someone that uses tail-water recovery systems (PeerTWR) will decrease the share of irrigated land estimated to use precision grade leveling by 0.173 ; unless you live along the Mississippi River (PeerTWR $\times$ River), the estimated share of land only decreases by $0.020(-0.175+0.155)$.

Producers with a peer that utilizes end block irrigation (PeerEndBlock) increase the share of irrigated land using precision grade leveling by 0.173 . Producers with peers that use end block irrigation and participate in regional conservation programs (PeerEndBlock $\times$ RegCon) are estimated to use 0.049 less $(0.173+-0.223)$ shares of land using precision grade leveling. Having a peer that uses alternative wetting and drying (PeerAltWetDry) increases the share of land that likely uses precision grade leveling by 0.184 . Plus, participating in a federal cost-share program for on-farm reservoirs and having a peer that uses alternating wetting and drying (PeerAltWetDry $\times$ Fed) also positively affects the estimated share of acres using precision grade leveling. If a producer has a peer that utilizes surge irrigation (PeerSurge), that decreases the share of acres utilizing preci- 
sion grade leveling by 0.105 , unless the producer also uses computerized hole selection (PeerSurge $\left.{ }^{*} \mathrm{CHS}\right)$, in which case the likelihood increases by $0.064(-0.105+0.169)$. For producers participating in a federal cost-share program for on-farm reservoirs and have a peer that uses surge irrigation (PeerSurge $\times$ Fed), the share of land using precision grade leveling decreases by $0.318(-0.105+-0.213)$.

Table 5. Marginal effects for the peer network variables to explain the share of irrigated acres using an irrigation practice.

\begin{tabular}{|c|c|c|c|c|c|c|}
\hline Variable & $\begin{array}{c}\text { Border } \\
\text { Irrigation }\end{array}$ & $\begin{array}{l}\text { Precision Grade } \\
\text { Leveling }\end{array}$ & $\begin{array}{l}\text { Warped Surface } \\
\text { Leveling }\end{array}$ & $\begin{array}{l}\text { End Block } \\
\text { Irrigation }\end{array}$ & $\begin{array}{l}\text { Cutback } \\
\text { Irrigation }\end{array}$ & Deep Tillage \\
\hline PeerPivot & & & & $-0.2113(-2.73)^{\mathrm{a}}$ & & \\
\hline PeerTWR & & $-0.174(-3.06)^{\mathrm{a}}$ & & & & $-0.033(0.58)$ \\
\hline PeerRes & & & $-0.152(-2.49)^{\mathrm{a}}$ & & $-0.127(-2.37)^{\mathrm{a}}$ & \\
\hline PeerCHS & & & & & & $-0.226(-3.42)^{a}$ \\
\hline PeerSurge & $0.138(0.93)$ & $-0.104(-1.59)$ & & & $0.094(1.92)^{b}$ & \\
\hline PeerFlowMeter & $-0.135(-1.55)$ & $-0.134(-2.13)^{b}$ & & $-0.041(-0.51)$ & $0.269(7.15)^{a}$ & \\
\hline PeerEndBlock & & $0.173(3.31)^{\mathrm{a}}$ & & $-0.348(-2.09)^{b}$ & $0.223(2.89)^{\mathrm{a}}$ & \\
\hline PeerScheduling & & & & & $-0.213(-3.27)^{\mathrm{a}}$ & $-0.116(-1.71)^{\mathrm{c}}$ \\
\hline PeerMulti-Inlet & & & & $0.180(1.90)^{\mathrm{c}}$ & $-0.143(-1.98)^{b}$ & $0.281(4.77)^{\mathrm{a}}$ \\
\hline PeerAltWetDry & & $0.184(2.56)^{\mathrm{a}}$ & & $-0.215(-1.92)^{b}$ & & $-0.109(-2.24)^{b}$ \\
\hline PeerTWR $\times$ River & & $0.154(1.70)^{\mathrm{c}}$ & & & & \\
\hline PeerTWR $\times$ ND & & & & & & $-0.330(-2.62)^{a}$ \\
\hline PeerRes $\times$ GP & & & $0.182(2.10)^{b}$ & & & \\
\hline PeerSurge $\times$ Fed & & $-0.213(-1.84)^{\mathrm{c}}$ & & & & \\
\hline PeerSurge $\times$ CHS & & $0.168(2.03)^{b}$ & & & & \\
\hline$\underset{\text { Con }}{\text { PeerSurge } \times \text { Reg }}$ & & & & & $0.243(5.08)^{a}$ & \\
\hline PeerFlowMeter $\times$ Ridge & & & & $0.220(1.93)^{b}$ & $0.226(2.33)^{b}$ & \\
\hline PeerFlowMeter $\times$ GP & $-0.679(-4.83)^{\mathrm{a}}$ & & & & & \\
\hline PeerFlowMeter $\times$ Fed & $0.482(3.57)^{\mathrm{a}}$ & & & & & \\
\hline $\begin{array}{l}\text { PeerFlowmeter } \times \\
\text { RegCon }\end{array}$ & & & & $0.206(1.68)^{\mathrm{c}}$ & & \\
\hline $\begin{array}{l}\text { PeerEndBlock } \times \\
\text { PartOther }\end{array}$ & & & & $-0.215(-2.73)^{\mathrm{a}}$ & & \\
\hline PeerEndBlock $\times$ RegCon & & $-0.223(-2.62)^{\mathrm{a}}$ & & $0.274(3.02)^{\mathrm{a}}$ & & \\
\hline PeerScheduling $\times$ Ridge & & & & & $-0.539(-8.69)^{\mathrm{a}}$ & \\
\hline \multicolumn{7}{|l|}{ PeerScheduling $\times$ CRP } \\
\hline $\begin{array}{c}\text { PeerMult- } \\
\text { Inlet } \times \text { PartOther }\end{array}$ & & & & & $0.157(1.74)^{\mathrm{c}}$ & \\
\hline PeerMult-Inlet $\times$ RegCon & & & & $-0.253(-1.76)^{\mathrm{c}}$ & & \\
\hline PeerAltWetDry $\times$ ND & & & & $0.523(2.76)^{\mathrm{a}}$ & & \\
\hline $\begin{array}{l}\text { PeerAltWetDry } \times \\
\text { PartOther }\end{array}$ & & & & $0.389(2.59)^{c}$ & & \\
\hline PeerAltWetDry $\times$ Fed & & $0.291(2.62)^{\mathrm{a}}$ & & & & \\
\hline Pseudo $R^{2}$ & 0.109 & 0.005 & 0.026 & 0.011 & 0.050 & 0.010 \\
\hline $\begin{array}{l}\text { LR equations: Chi } \\
\text { squared statistics } \chi^{2}\end{array}$ & $28.27^{\mathrm{a}}$ & $5.23^{b}$ & $52.25^{\mathrm{a}}$ & $5.56^{\mathrm{b}}$ & $33.01^{\mathrm{a}}$ & 2.39 \\
\hline Number of observation & 20 & 159 & 58 & 57 & 18 & 81 \\
\hline
\end{tabular}

${ }^{a}-1 \%, b-5 \%, c-10 \%$ significance. $Z$ statistics from the bivariate sample selection model estimates in parentheses. 
Table 6. Marginal effects for the farm, irrigation, and socioeconomics variables to explain the share of irrigated acres using an irrigation practice.

\begin{tabular}{|c|c|c|c|c|c|c|}
\hline Variable & $\begin{array}{l}\text { Border } \\
\text { Irrigation }\end{array}$ & $\begin{array}{l}\text { Precision Grade } \\
\text { Leveling }\end{array}$ & $\begin{array}{c}\text { Warped Surface } \\
\text { Leveling }\end{array}$ & $\begin{array}{l}\text { End Block } \\
\text { Irrigation }\end{array}$ & $\begin{array}{l}\text { Cutback } \\
\text { Irrigation }\end{array}$ & Deep Tillage \\
\hline TotalIrr.Acres & & $-0.000(-2.33)^{b}$ & & & & $-0.000(-3.51)^{a}$ \\
\hline PercentRice & & & & & $0.0019(1.74)^{c}$ & \\
\hline \multicolumn{7}{|l|}{ PivotRows } \\
\hline WarpedSurface & $0.0059(4.72)^{\mathrm{a}}$ & & & & & \\
\hline EndBlock & $-0.009(-6.61)^{\mathrm{a}}$ & & & & & \\
\hline IrrSoy & & & $0.173(1.67)^{\mathrm{c}}$ & $-0.191(-1.66)^{c}$ & & \\
\hline IrrigatedRice & & & & & $-0.000(-2.18)^{b}$ & \\
\hline IrrigatedCotton & & $0.001(1.88)^{c}$ & & & & \\
\hline ETAtmometer & & & $0.271(1.82)^{c}$ & & & \\
\hline Ridge & & & $0.232(2.74)^{\mathrm{a}}$ & & & \\
\hline River & & & $0.276(1.98)^{b}$ & & & \\
\hline \multicolumn{7}{|l|}{ ND } \\
\hline \multicolumn{7}{|l|}{ SD } \\
\hline TWR & & & & $-0.228(-2.75)^{a}$ & & \\
\hline PartCRP & & & & & & $-0.193(-3.90)^{a}$ \\
\hline PartEQIP & & & & & & $0.229(3.87)^{\mathrm{a}}$ \\
\hline \multicolumn{7}{|l|}{ PartRegCon } \\
\hline \multicolumn{7}{|l|}{ PartOther } \\
\hline ComputerHole & & & & & & $0.138(2.44)^{b}$ \\
\hline \multicolumn{7}{|l|}{$\begin{array}{l}\text { Computer } \\
\text { Schedule }\end{array}$} \\
\hline YieldCorn & $-0.003(-7.51)^{a}$ & & & $-0.000(-1.74)^{c}$ & $-0.000(-2.27)^{b}$ & \\
\hline \multicolumn{7}{|l|}{ CoverCrop } \\
\hline PrecisionGrade & & & & & & $0.000(2.21)^{b}$ \\
\hline PrecisionLevelEasy & & $0.099(1.76)^{c}$ & & & & \\
\hline $\begin{array}{l}\text { NoPrecision } \\
\text { LevelCost }\end{array}$ & & & & & & $-0.175(-1.80)^{\mathrm{c}}$ \\
\hline ZeroGrade & & & & & & $-0.007(-3.06)^{a}$ \\
\hline Multi-Inlet & & & $0.0015(2.77)^{a}$ & & & $0.001(2.14)^{b}$ \\
\hline AgEdu & & & & & $0.100(1.82)^{c}$ & \\
\hline Bach & $-0.273(-2.76)^{a}$ & & & & $-0.442(-5.23)^{a}$ & \\
\hline AdvEdu & & $0.201(2.31)^{b}$ & & $0.432(2.29)^{b}$ & $0.683(6.26)^{a}$ & \\
\hline \multicolumn{7}{|l|}{ IncHigh } \\
\hline IncNA & & & & & & $-0.116(-2.17)^{b}$ \\
\hline PH60 & & & & & $-0.003(-1.81)^{\mathrm{c}}$ & \\
\hline AWS & & & & $0.159(2.33)^{b}$ & & \\
\hline РРТ2013 & & $-0.021(-2.59)^{\mathrm{c}}$ & & & & $-0.020(-2.74)^{a}$ \\
\hline РPT2015 & & & & & $0.009(2.24)^{b}$ & \\
\hline GDD2013 & & $-0.000(-1.74)^{c}$ & & & & \\
\hline Loam & & $0.010(2.30)^{b}$ & & $0.020(2.41)^{\mathrm{c}}$ & & $0.011(1.95)^{b}$ \\
\hline Silt & & & & & $-0.004(-1.65)^{\mathrm{c}}$ & \\
\hline Sand & $-0.007(-1.70)^{\mathrm{c}}$ & & & & & \\
\hline OpenWater & & & & & & $-0.003(-2.34)^{b}$ \\
\hline CanalDitch & & & & $-0.006(-2.05)^{b}$ & $0.011(7.25)^{a}$ & $-0.004(-2.17)^{b}$ \\
\hline BarrierPipe & $1.769(3.45)^{\mathrm{a}}$ & & & & & \\
\hline Pseudo $\mathrm{R}^{2}$ & 0.109 & 0.005 & 0.026 & 0.011 & 0.050 & 0.010 \\
\hline $\begin{array}{c}\text { LR equations: } \\
\text { Chi-squared statistics } \chi^{2}\end{array}$ & $28.27^{a}$ & $5.23^{b}$ & $52.25^{a}$ & $5.56^{\mathrm{b}}$ & $33.01^{a}$ & 2.39 \\
\hline Number of observation & 20 & 159 & 58 & 57 & 18 & 81 \\
\hline
\end{tabular}


If a producer lives in the Grand Prairie and knows someone using reservoirs (PeerRes $\times \mathrm{GP}$ ), they are estimated to have $0.030(-0.152+0.183)$ more shares that utilize warped surface leveling, but in the other regions, having a peer that uses reservoirs (PeerRes) decreases the share of land utilizing warped surface leveling by 0.152 . On a different note, producers that know someone using end block irrigation are likely to use 0.082 of the irrigated land of end-blocking irrigation instead of the average 0.430 . A producer that participates in regional conservation programs or other programs and has a peer that uses end block irrigation will likely have $0.073(-0.348+0.275)$ and $0.563(-0.348+-0.215)$ fewer shares of land using end block. Producers with a peer that uses center-pivot irrigation (PeerPivot) are likely to have 0.211 less irrigated land that utilizes end block irrigation. Participating in a regional conservation program and having a peer that uses flow meters (PeerFlowmeter $\times$ RegCon) will increase the share of irrigated land that utilizes end block irrigation, yet having a peer that uses multiple inlet irrigation (PeerMultiInlet $\times$ RegCon) decreases the share of land. Producers that live along Crawley's Ridge having a peer that uses a flow meter (PeerFlowmeter $\times$ Ridge) increases the share of land using end block irrigation by $0.179(-0.041+0.221)$. Knowing someone that uses alternative wetting and drying (PeerAltWetDry) decreases the share of land using end block irrigation unless the farm is located in the North Delta (PeerAltWetDry $\times$ ND) or participates in other conservation programs (PeerAltWetDry $\times$ PartOther).

Living in the North Delta and having a peer that uses tail-water recovery (PeerTWR $\times N D$ ) decreases the share of estimated land that utilizes deep tillage - at the same time, having a peer that uses tail-water recovery and that lives elsewhere increases the share of acres that utilizes deep tillage. Knowing someone who uses computerized hole selection (PeerCHS) decreases the share of irrigated land that uses deep tillage by 0.226 . Having a peer that uses scheduling (PeerScheduling) or alternative wetting and drying (PeerAltWetDry) decreases the share of irrigated land that uses deep tillage by a little more than 0.100. Lastly, having a peer that uses multiple inlet irrigation (PeerMultiInlet) increases irrigated land shares that use deep tillage by 0.282 . Knowing someone that uses precision leveling (PeerPLevel) increases the share of estimated irrigated cover-crop land by 0.237 .

If a producer has a peer that uses surge irrigation (PeerSurge), they will likely have more irrigated land that uses cutback irrigation, especially if they also participate in a regional conservation program (PeerSurge $\times$ RegCon). Producers that live along Crowley's Ridge and know someone who uses flow meters (PeerFlowmeter $\times$ Ridge) will likely have $0.496(0.269+0.227)$ more shares of irrigated land that uses cutback irrigation. In comparison, producers in other regions with peers using flow meters (PeerFlowMeter) will likely only have 0.269 more shares of irrigated land. Knowing someone that uses end block irrigation (PeerEndBlock) increases the estimated share of land that utilizes cutback irrigation by 0.223 . Knowing someone that uses a form of scheduling (PeerScheduling) decreases the share of irrigated land that utilizes cutback irrigation by 0.213 ; when the farm is also located along Crowley's Ridge, it is estimated to decrease by an additional 0.539 for a total decrease of 0.753 (PeerScheduling $\times$ Ridge). Having a peer that uses multiple inlet irrigation (PeerMultiInlet) decreases the share of irrigated land that uses cutback irrigation unless the producer also participates in other conservation programs (PeerMultiInlet $\times$ PartOther). Having a peer that uses reservoirs (PeerRes) decreases the irrigated land share utilizing cutback irrigation by an estimated 0.128 .

Table 6 shows the marginal effects for the explanatory farm, irrigation, and socioeconomic variables that influence the share of land that uses a particular practice. Using end block irrigation (EndBlock), having sandy soil (Sand), and knowing the estimated corn yield (YieldCorn) have a negative effect on the share of land in border irrigation, while warped surface leveling has a positive effect. When looking at education, having a bachelor's degree (Bach) decreases the irrigated acres' share that uses border irrigation to 0.257 . Producers that use barrier pipes are likely to have 1.76 more shares of land that use border irrigation. 
If a producer reported using precision leveling on their farm because it makes things easier (PrecisionLevelEasy), then the share of irrigated land that uses precision grade leveling increases by 0.099 . Producers with an advanced education (AdvEdu) are estimated to have 0.202 more shares of irrigated land that utilize precision grade leveling. Producers with loamy soils (Loam) will likely have a larger share of acres utilizing precision grade leveling. A farm's location has a significant impact on the share of land that uses warped surface leveling. The producers that live along the Mississippi River (River) and Crowley's Ridge (Ridge) are expected to have a higher share of acres that use warped surface leveling. If a producer uses atmometers or other similar technologies (ETAtmometer), it is estimated that the farm will have 0.271 more shares of irrigated land that uses warped surface leveling. Producers that grow irrigated soybeans (IrrSoy) will likely have a share of irrigated land using warped surface leveling that is 0.174 larger. Unlike warped surface leveling, if a producer has irrigated soybeans (IrrSoy), they are estimated to have 0.192 fewer shares of irrigated land using end block irrigation. Having a master's degree (AdvEdu) increases the share of irrigated land that uses end block irrigation to 0.862 . The use of tail-water recovery systems (TWR) reduces the share of irrigated land that uses end block irrigation. Meanwhile, having a root zone between 0 to 59 inches with available water storage (AWS) and loamy soils (Loam) increases the share of irrigated acres that uses end-blocking irrigation.

Participation in a conservation reserve program (PartCRP) reduces the share of irrigated acres utilizing deep tillage by 0.193 . In contrast, participation in the environmental quality incentive program (PartEQIP) increases the share of deep-tillage-irrigated land by 0.229. Computerized hole selection (ComputerHole), precision grade leveling (PrecisionGrade), loamy soils (Loam), and multiple inlet irrigation (MultiInlet) increase the share of land using deep tillage. Producers that do not use precision leveling (NoPrecisionLevelCost) because it is too expensive will likely reduce the share of deep tillage land by 0.176 . The producers that did not report their income (IncNA) will likely have a lower share of irrigated land that uses deep tillage by 0.117 . Other variables that will slightly reduce the share of land that uses deep tillage include zero grade leveling (ZeroGrade), artificial paths (ArtificalPath), canal ditches (CanalDitch), and the amount of growing season precipitation (PPT2013). If a producer has some agriculture education, then the producer is likely to use cutback irrigation for 0.101 more shares of irrigated land. Producers with bachelor's degrees (Bach) will likely decrease the shares of irrigated land in cutback irrigation by 0.443 , while producers with a master's degree or higher (AdvEdu) should increase the share of cutback irrigated land by 0.684 .

\section{Discussion}

Border irrigation is influenced by three peer variables. The field management practice shows an average number of two significant peer variables that influence the use. All of the irrigation techniques that we evaluated have at least one peer variable that is significant, but deep tillage has the most peer variables with large magnitudes. The likelihood of end-block irrigation from peer influence ranges from $-42 \%$ for a peer that uses multiple inlet irrigation and participates in a federal cost share program to $41 \%$ for a peer that uses end-block irrigation.

Producers that have peers using end block irrigation are more likely to use end block irrigation themselves; this is especially true if the producer also participates in a federal cost-share program for on-farm reservoirs. In [8], it was found that living in the same neighborhood could increase the likelihood of a learning link by an average of $13 \%$. Girls with more friends using the technology adopted it faster, although by the end of the study, usage rates between all the girls with friends using the technology were similar [26]. The interaction of the participation in a federal cost-share program for on-farm reservoirs with having a peer that also uses end block irrigation increases the likelihood of use by an additional $37 \%$. The same can be said for producers that have peers using precision grade leveling; they are more likely to use it themselves and even more so if they participate in 
a federal cost-share program for on-farm reservoirs. Federal programs offer cost-share funding for irrigation practices the producers use, so the availability of money could be a plausible explanation for the additional increase in likelihood. Producers participating in these cost-share programs could simply have a heightened awareness of conservation practices in general, which could also be a plausible explanation for the additional increase in likelihood.

The results reveal a complementary or substitution relationship between these techniques based on the peer effects. Producers are less likely to use border irrigation if they have a peer using computerized hole selection, suggesting that those practices are substitutes. Yet, producers are more likely to use deep tillage if they have a peer that uses computerized hole selection, suggesting that those practices are used together. Having a peer that uses pivot irrigation increases the use of precision grade leveling by $2 \%$. If a producer has a peer that uses multiple inlet irrigation, they will probably not use end block irrigation or warped surface leveling. Producers that have peers using water storage or recovery technology are likely to use field management practices on a smaller share of land, which suggests that water storage or recovery is a substitute for field management. Multiple inlet irrigation is likely used instead of either of these techniques, so it could be considered a substitute. Having a peer that uses multiple inlet irrigation and participation in a federal cost-share program for on-farm reservoirs is $63 \%$ less likely to use end block irrigation. Warped surface leveling and alternating wetting and drying are also substitutes $14 \%$ of the time. In general, water flow control technologies seem to be substitutes for field management practices, when looking at the likelihood of use.

The interaction variables reveal homogeneous peer effects by location and program participation for border irrigation, and end block irrigation. Having a peer that uses surge irrigation has a positive effect on the use of border irrigation. Having a peer that uses surge irrigation while participating in a federal cost-share program for on-farm reservoirs also has a positive effect on the use of border irrigation. When looking at end block irrigation, having peers that use flow meters or multiple inlet irrigation reduces the likelihood of use, and this is even more so when interacting with location and participation in a federal cost-share program for on-farm reservoirs, respectively. The interaction of different locations and peer uses of multiple inlet irrigation varies the use of deep tillage. Peer use of computerized hole selection increases the use of deep tillage, and it does even more so along Crowley's Ridge and Grand Prairie, but it decreases the use of deep tillage in the South Delta. All of the significant location interactions with peer use of scheduling increase the use of deep tillage. The use of precision grade leveling increases if a peer uses pivot irrigation, except for the producers that live along Crowley's Ridge. Warped surface leveling is negatively influenced by having a peer that uses multiple inlet irrigation, but when it interacts with the locations Crowley's Ridge, the Grand Prairie, or the North Delta, it positively influences the use. The effect of multiple inlet irrigations on warped surface leveling varies with location more than any other variable in this model.

Producers that live along the Mississippi river are less likely to use border irrigation in their farm. However, producers that live in the South Delta are $50 \%$ more likely to use warped surface leveling. Along with location, the type of crops can also influence a producer's choice to use a particular practice or not. Planting an irrigated field with soybeans or rice increases the likelihood of using warped surface leveling. Producers with advanced education are not likely to deep-till their fields, and producers with some agriculture education are even less likely to deep-till their fields. This could be attributed to a heightened awareness of the long-term environmental impacts, such as erosion, emphasized in many agriculture educational programs. Ref. [6]'s study indicated that education did play a part in a producer's decision to switch irrigation technologies, but the effects are minimal and insignificant. Ref. [27] found that for every additional year of education, the chances of adopting irrigation scheduling decreases, but it is also insignificant at the 10th percentile. 
Having a peer that uses surge irrigation reduces the share of land using border irrigation and precision grade leveling by about 0.10 , suggesting that these techniques are weak substitutes. The share of land that uses cutback irrigation increases, suggesting that surge irrigation is a complement, and previously surge irrigation was suggested to be a substitute. End block irrigation has the most substitutes when evaluating the influence on the share of irrigated land. This list includes peers that use pivot irrigation with -0.21 , peers that use flow meters with -0.04 , and peers that use alternating wetting and drying with -0.21 . Yet, end block irrigation and cutback irrigation are complements, as having a peer that uses end block irrigation increases the share of land using cutback irrigation. Having a peer who uses flow meters decreases the amount of land using border irrigation, especially producers that live in the Grand Prairie or participate in a federal cost-share program for on-farm reservoirs, making them a substitute. The interaction of living in the Grand Prairie and having a peer that uses flow meters has the largest magnitude effect in this model, with a 0.81 reduction in the amount of land using border irrigation. Precision grade leveling complements end-blocking irrigation and alternative wetting and drying but substitutes with surge irrigation and flow meters.

Producers living along the ridge or by the river are likely to have more land using warped surface leveling than other locations. If a producer's farm has loamy soils, the share of land using deep tillage is higher than other soil types. The level of education a producer has influences the share of land utilizing border irrigation, precision grade leveling, end block irrigation, and cutback irrigation. Producers with a bachelor's degree are shown to have a smaller share of land using water flow control technology. However, a producer with at least a master's degree is more likely to use cutback irrigation, endblocking irrigation, and precision grade leveling. The miles of barrier pipe (BarrierPipe) that connect waterbodies separated by dams, weirs, and other artificial barriers has the largest magnitude effect on the proportion of land using a border than any other variable. A producer's participation in government programs influences the share of land utilizing deep tillage. Producers use deep tillage on a smaller share of land if they participate in a conservation reserve program. Participation in an environmental quality incentives program increases the amount of land using deep tillage.

\section{Conclusions}

Producers should try and utilize efficient irrigation practices, to continue irrigating their crop without depleting the water source; therefore, factors influencing the use of irrigation practices are worthwhile to investigate as there have been significant groundwater depletions within the state. We examined how these peer networks interact with location and participation in programs by changing the initial effects. For example, a producer that has a peer using multiple inlet irrigation is $37 \%$ less likely to use warped surface leveling; however, if the producer has a peer that uses multiple inlet irrigation and lives in the Grand Prairie, the likelihood of using warped surface leveling increases by $13 \%(-37 \%+50 \%)$. Having a peer that uses multiple inlet irrigation reduces the likelihood that a producer uses end-blocking irrigation on their farm by $20 \%$; however, if a producer has a peer that uses multiple inlet irrigation, they are likely to use end block irrigation on 0.183 more shares of irrigated land.

When evaluating the model as a whole, the largest average magnitude effect occurs if the irrigation techniques interact with the various locations. Warped surface leveling use is negatively influenced by having a peer that uses multiple inlet irrigation $(-37 \%)$, but when it interacts with the locations Crowley's Ridge (-2\%), the Grand Prairie $(13 \%)$, or the North Delta $(12 \%)$, the use is positively influenced. We find that location can not only reinforce an outcome but can even go as far as reversing the initial peer effect.

End block irrigation has the most substitutes when evaluating the influence on the share of irrigated land. The list of peer variables influencing the share of land using end-blocking irrigation is a peer using pivot irrigation with -0.21 , peers that use flow meters with -0.04 , and peers that use alternating wetting and drying with -0.21 as 
well. We likely see the decrease in end blocking based on peers using pivot irrigation because end blocking is for furrow irrigation, while center pivot irrigation is a sprinkler irrigation system. If a producer has someone sharing knowledge, asking questions, or sharing equipment with them, it makes sense that they use the technologies. Having more peers that use a particular technology increases the chance of adopting the same technology [10]. Producers in Northern Mozambique with a social network containing $1-5$ adopters increase the propensity to adopt sunflower seeds by 0.27 , while having a social network containing 6-10 adopters increases the propensity by 0.58 [10]. For the nearestneighbor peer definition, additional peer adopters increase the probability of adoption. Once the number of peer adopters reaches 9 , an additional peer adopter does not make much difference [11].

The conservation programs have an influence through the peer effects that are sometimes positive and other times negative. When looking at the share of land using field management practices, the interactions with participation in a regional conservation partnership program, and peer variables, the sign of the effect is opposite of just the peer variable. For example, having a peer that uses end blocking shows a 0.17 increase in the share of land using precision leveling, but having a peer that uses end blocking and the producer participating in a regional conservation partnership program, the share of land using precision grade leveling shows a 0.22 decrease in the share of land. These results suggest that participation in this program can change the way a producer thinks, and they do not rely as much on peers as producers not in this program.

Physical characteristics of a farm can be a strong contributor to the techniques a producer uses, but we found that interactions with peers are the strongest contributors. A majority of the physical variables are not significant when looking at the use and share of land using a particular technique. Producers with advanced education are not likely to use deep tillage on their farms, and producers with some agriculture education are even less likely to deep-till their fields. While deep tillage helps water reach the crop roots efficiently, producers with education would likely be aware of the long-term erosion effects as well. We find that varying education levels can significantly increase or decrease a producer's use of particular irrigation technologies, which is different for some of the other similar studies. According to [7], if a producer had more than nine years of education, they adopt drip irrigation quicker than producers with less education. However, in [8], it was found that education can increase or decrease the adoption of a new technology depending on what village they live in.

These results extend the literature on variables and peer networks that influence the use and share of irrigated acres in specific techniques in the Arkansas Delta. It helps bridge the gap between literature evaluating irrigation technologies and literature evaluating the effects of peer networks. Further research is needed to account for the potential differences of peer effects in different regions in the United States. In addition, studies with additional peer information, such as the number of peers, type or length of relationships, and frequency of their interactions, could provide additional insight on how peer networks influence irrigation technology uses.

Author Contributions: K.K., Q.H. and L.J.K. conceived and designed the study; V.B. and K.K. performed the analysis; V.B., K.K. and C.H. analyzed the data; V.B. and K.K. wrote the paper. All authors have read and agreed to the published version of the manuscript.

Funding: The authors received support for this study from Arkansas Rice Research and Promotion Board and the Arkansas Soybean Promotion Board.

Institutional Review Board Statement: Not applicable.

Informed Consent Statement: Not applicable.

Data Availability Statement: The data used for this study are proprietary.

Conflicts of Interest: The authors declare no conflict of interest. 


\section{References}

1. Hess, T.M.; Knox, J.W. Water savings in irrigated agriculture: A framework for assessing technology and management options to reduce water losses. Outlook Agric. 2013, 42, 85-91. [CrossRef]

2. Koundouri, P.; Nauges, C.; Tzouvelekas, V. Technology Adoption under Production Uncertainty: Theory and Application to Irrigation Technology. Am. J. Agric. Econ. 2006, 88, 657-670. [CrossRef]

3. Frisvold, G.; Bai, T. Irrigation Technology Choice as Adaptation to Climate Change in the Western United States. J. Contemp. Water Res. Educ. 2016, 158, 62-77. [CrossRef]

4. Green, G.; Sunding, D.; Zilberman, D.; Parker, D. Explaining Irrigation Technology Choices: A Microparameter Approach. Am. J. Agric. Econ. 1996, 78, 1064-1072. [CrossRef]

5. Schuck, E.C.; Frasier, W.M.; Webb, R.S.; Ellingson, L.J.; Umberger, W.J. Adoption of More Technically Efficient Irrigation Systems as a Drought Response. Int. J. Water Resour. Dev. 2005, 21, 651-662. [CrossRef]

6. Wheeler, S.; Bjornlund, H.; Olsen, T.; Klein, K.K.; Nicol, L. Modelling the adoption of different types of irrigation water technology in Alberta, Canada. WIT Trans. Ecol. Environ. 2010, 134, 189-201. [CrossRef]

7. Genius, M.; Koundouri, P.; Nauges, C.; Tzouvelekas, V. Information Transmission in Irrigation Technology Adoption and Diffusion: Social Learning, Extension Services, and Spatial Effects. Am. J. Agric. Econ. 2014, 96, 328-344. [CrossRef]

8. Maertens, A.; Michelson, H.; Nourani, V. How Do Farmers Learn from Extension Services? Evidence from Malawi. Am. J. Agric. Econ. 2021, 103, 569-595. [CrossRef]

9. Sampson, G.S.; Perry, E.D. Peer effects in the diffusion of water-saving agricultural technologies. Int. Assoc. Agric. Econ. 2019, 50, 693-706. [CrossRef]

10. Bandiera, O.; Rasul, I. Social Networks and Technology Adoption in Northern Mozambique. Econ. J. 2006, 116, 869-902. [CrossRef]

11. Sampson, G.S.; Perry, E.D. The Role of Peer Effects in Natural Resource Appropriation-The Case of Groundwater. Am. J. Agric. Econ. 2018, 101, 154-171. [CrossRef]

12. Conley, T.G.; Udry, C. Learning about a New Technology: Pineapple in Ghana. Am. Econ. Rev. 2010, 100, 35-69. [CrossRef]

13. Ward, P.S.; Pede, V.O. Capturing social network effects in technology adoption: The spatial diffusion of hybrid rice in Bangladesh. Aust. J. Agric. Resour. Econ. 2014, 59, 225-241. [CrossRef]

14. West, G.; Kovacs, K.; Henry, C.; Engram, I.; Huang, Q. Arkansas Irrigation; Division of Agriculture Research \& Extension, University of Arkansas: Fayetteville, AR, USA, 2017.

15. National Agricultural Statistics Service (NASS). Table 10: Irrigation: 2017 and 2012; Census of Agriculture, USDA: 2017. Available online: www.nass.usda.gov/Publications/AgCensus/2017/Full_Report/Volume_1,Chapter_2_US_State_Level/ (accessed on 11 June 2020).

16. National Agricultural Statistics Service (NASS). Table 2: Irrigated Farms by Acres Irrigated: 2018 and 2013; Census of Agriculture, USDA: 2018. Available online: www.nass.usda.gov/Publications /AgCensus/2017/Online_Resources/Farm_and_Ranch_ Irrigation_Survey/index.php (accessed on 25 June 2020).

17. NIDIS. Arkansas I Drought.gov: 2020. In Arkansas. Available online: www.drought.gov/states/arkansas\#: \{\}:text=The\%20U.S. \%20Drought $\% 20$ Monitor\%20started,affected\%2053.6\%25\%20of\%20Arkansas\%20land (accessed on 25 June 2020).

18. National Agricultural Statistics Service (NASS). Table 29: Gravity Irrigation in Fields in the Open; Census of Agriculture, USDA: 2018. Available online: www.nass.usda.gov/Publications / AgCensus/2017/Online_Resources/Farm_and_Ranch_Irrigation_ Survey/index.php (accessed on 25 June 2020).

19. National Agricultural Statistics Service (NASS). Table 30: Sprinkler Irrigation in Fields in the Open; Census of Agriculture, USDA: 2018. Available online: www.nass.usda.gov/Publications / AgCensus/2017/Online_Resources/Farm_and_Ranch_Irrigation_ Survey /index.php (accessed on 25 June 2020).

20. National Agricultural Statistics Service (NASS). Table 39: Water Management Practices Used by Producers with Gravity Systems for Acres in the Open; Census of Agriculture, USDA: 2018. Available online: www.nass.usda.gov/Publications/AgCensus/2017 /Online_Resources/Farm_and_Ranch_Irrigation_Survey/index.php (accessed on 25 June 2020).

21. National Agricultural Statistics Service (NASS). Table 25: Barriers to Making Improvements to Reduce Energy Use or Conserve Water; Census of Agriculture, USDA: 2018. Available online: www.nass.usda.gov/Publications/AgCensus/2017/Online_ Resources/Farm_and_Ranch_Irrigation_Survey/index.php (accessed on 30 June 2020).

22. National Agricultural Statistics Service (NASS). Table 24: Technical and Financial Assistance Received During the Past Five Years for Irrigation or Drainage Improvements: 2018; Census of Agriculture, USDA: 2018. Available online: www.nass.usda.gov/ Publications /AgCensus/2017/Online_Resources/Farm_and_Ranch_Irrigation_Survey/index.php (accessed on 30 June 2020).

23. Henry, C.; Krutz, L.; Henggeler, J.; Levy, R.; Huang, Q.Q.; Kovacs, K. A Survey of 2015 Mid-South Irrigation Practices: Report to the Mid-South Soybean Board and Dataset; Mid-South Soybean Board, University of Arkansas Division of Agriculture: Fayetteville, AR, USA, 2020.

24. Oregon State University; PRISM Climate Group, Oregon State University, USDA Risk Management Agency. 2021. Available online: https:/ / prism.oregonstate.edu/explorer/ (accessed on 15 June 2021).

25. Arkansas GIS. Water; Arkansas GIS Office, Arkansas Department of Transformation and Shared Services: Little Rock, AR, USA, 2021. Available online: http:/ / gis.arkansas.gov/product-category/data/water/ (accessed on 15 June 2021). 
26. Oster, E.; Thornton, R. Determinants of technology adoption: Peer effects in menstrual cup take-up. J. Eur. Econ. Assoc. 2012, 10, 1263-1293. [CrossRef]

27. Engler, A.; Jara-Rojas, R.; Bopp, C. Efficient use of Water Resources in Vineyards: A Recursive joint Estimation for the Adoption of Irrigation Technology and Scheduling. Water Resour. Manag. 2016, 30, 5369-5383. [CrossRef] 